\title{
Improving adolescent knowledge of emergency contraception: challenges and solutions
}

This article was published in the following Dove Press journal:

Open Access Journal of Contraception

22 November 2016

Number of times this article has been viewed

\section{Sujatha Seetharaman \\ Sophia Yen \\ Seth D Ammerman}

Division of Adolescent Medicine, Stanford University Medical Center, Palo Alto, CA, USA

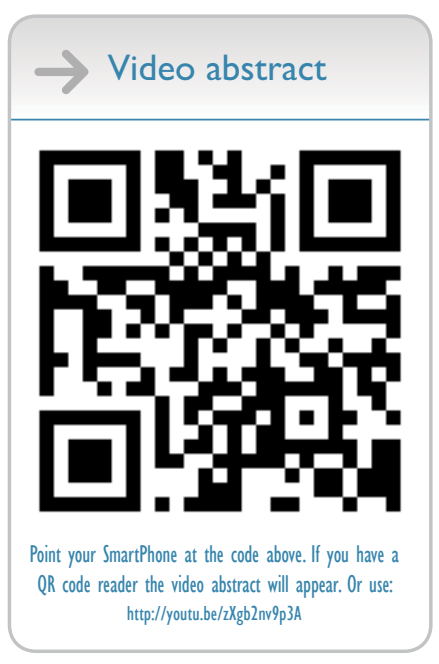

Correspondence: Seth D Ammerman Division of Adolescent Medicine, Stanford University Medical Center, 770 Welch Road - Suite 100, Palo Alto, CA 94304, USA

Email seth.ammerman@stanford.edu

\begin{abstract}
Globally, unintended adolescent pregnancies pose a significant burden. One of the most important tools that can help prevent unintended pregnancy is the timely use of emergency contraception (EC), which in turn will decrease the need for abortions and complications related to adolescent pregnancies. Indications for the use of EC include unprotected sexual intercourse, contraceptive failure, or sexual assault. Use of EC is recommended within 120 hours, though is most effective if used as soon as possible after unprotected sex. To use EC, adolescents need to be equipped with knowledge about the various EC methods, and how and where EC can be accessed. Great variability in the knowledge and use of EC around the world exists, which is a major barrier to its use. The aims of this paper were to 1) provide a brief overview of EC, 2) discuss key social determinants affecting knowledge and use of EC, and 3) explore best practices for overcoming the barriers of lack of knowledge, use, and access of EC.
\end{abstract}

Keywords: emergency contraception, adolescents, unintended pregnancy, unprotected sexual intercourse

\section{Background}

Despite significant declines in adolescent pregnancy in the past two decades, it continues as a significant burden globally, with approximately 16 million (11\%) of all births worldwide to young women 15-19 years. ${ }^{1}$ Most of these pregnancies are unintended, and 95\% occur in low- and middle-income countries. ${ }^{1}$ Global rates of unintended adolescent pregnancies vary widely. A recent review article showed that among the 21 countries with complete statistics, the pregnancy rate among 15- to 19-year-olds was highest in the US (57 pregnancies per 1,000 females) and lowest in Switzerland (eight pregnancies per 1,000 females). ${ }^{2}$ In those countries with incomplete statistics, higher rates were reported in some former Soviet countries and highest rates in Mexico and sub-Saharan African countries. ${ }^{2}$ The proportion of teen pregnancies that ended in abortion ranged from $17 \%$ in Slovakia to $69 \%$ in Sweden. ${ }^{2}$ Among 15 - to 19 -year-olds globally, complications secondary to pregnancy, childbirth, and unsafe abortions are the second-leading cause of mortality. ${ }^{1}$ Adolescent pregnancies are also associated with an array of negative social and economic consequences, compromising adolescents' future educational and economic opportunities. ${ }^{3}$

Although there are several causes for unintended pregnancies, one of the most important tools that can help in preventing them is the timely use of emergency contraception (EC). EC can help prevent the need for abortions and prevent maternal and 
infant complications by offering a second chance to prevent pregnancy after unprotected intercourse, contraceptive failure, or sexual assault. Due to the fact that no contraceptive has $100 \%$ efficacy, adolescents need access to EC as a backup method.

To use EC, adolescents need to be equipped with knowledge about the various methods and how they can have access to them. Great variability in the knowledge and use of EC exists around the world, though the US and European countries have high EC awareness. ${ }^{4,5}$ In $80 \%$ of the 45 countries studied, $<3 \%$ of sexually active women aged $14-49$ years had ever used EC. ${ }^{4}$ A 2010 policy report found that awareness of EC ranged from 6\% among married women in Indonesia to a high of $35 \%$ among married women in Ghana; however, $<3 \%$ of women reported that they actually used EC. ${ }^{5}$ Additionally, availability and cost of EC varies around the world. ${ }^{5} \mathrm{~A}$ study by the American Society for Emergency Contraception showed that even though levonorgestrel (LNG) methods of EC have been made available over the counter, many of them are being sold behind the counter or are locked up, due to high cost of the product (US\$48 on average). ${ }^{6}$

The objectives of this paper are to provide a brief overview of EC, discuss key social determinants affecting knowledge and use of EC, and explore best practices for overcoming barriers to lack of knowledge and use of EC.

\section{Brief overview of EC Brief history of EC}

The roots of modern EC date back to the 1920s, when high doses of ovarian estrogen extracts were found to interfere with pregnancy in mammals. Veterinarians were the first to apply this method to prevent unwanted pregnancies in horses and dogs. Evidence remained scattered until the 1960s, when physicians in the Netherlands administered high-dose estrogen to a 13-year-old girl who was a rape victim. In the 1970s, the Yuzpe regimen was introduced, which consisted of a combined-hormone regimen (100 $\mu \mathrm{g}$ ethinyl estradiol and $1 \mathrm{mg}$ norgestrel, given as two doses 12 hours apart) that replaced the high-dose-estrogen EC methods. The Yuzpe regimen replaced high-dose estrogen chiefly because it resulted in a lower incidence of side effects. At the same time, research on regimens omitting estrogen began, predominantly in Latin America. The Yuzpe regimen, though very popular until the beginning of the twenty-first century, has been surpassed by LNG EC products, due to LNG's higher efficacy and fewer side effects. Around the same time, the copper intrauterine device (IUD) was introduced as the only nonhormonal method of EC. Ulipristal acetate (UPA), a selective progesterone-receptor modulator, was approved as EC in the UK in 2009 and in 2010 in the US.

\section{Various methods of EC (from most effective to least effective)}

Both hormonal and non-hormonal methods of EC exist.

\section{Nonhormonal EC}

The copper IUD is the only nonhormonal method and the most effective EC method. The usual protocol is to insert it within 5 days of unprotected sex or contraceptive failure or up to 5 days after ovulation. Studies have shown that IUDs can be inserted as EC after 5 days ${ }^{7}$ and anytime in the cycle if a highly sensitive pregnancy test is negative. ${ }^{8,9}$ The primary mechanism of the copper IUD is an inhibitory effect of copper ions on sperm that prevents fertilization. The copper IUD also adversely affects endometrial receptivity. An advantage of the copper IUD is that it can be left in utero after its use as EC, serving as highly effective, long-acting reversible contraception for 10-12 years. Few contraindications for the copper IUD as an EC method exist. Specific contraindications are current pregnancy, current pelvic inflammatory disease, allergy to copper, and uterine anomalies. Risks of expulsion, infection, and/or perforation are low with the copper IUD. ${ }^{10}$

\section{Hormonal methods}

Ulipristal acetate

This is the most effective and newest form of EC pill. It is currently available in 79 countries, ${ }^{11}$ and is given as $30 \mathrm{mg}$ in a single dose orally. It is a selective progesterone-receptor modulator. ${ }^{12}$ One study reported that UPA delays ovulation. ${ }^{12}$ A 2010 meta-analysis of studies reported that for those women treated with UPA within 72 hours of unprotected intercourse, the risk of pregnancy was almost half that of those receiving $\mathrm{LNG}$, and if given within 24 hours, the risk of pregnancy was reduced by two-thirds in those receiving UPA compared to LNG. ${ }^{13}$ There are no medical contraindications for the use of UPA other than pregnancy. It is effective for up to 5 days after contraceptive failure, and efficacy does not decline over the 5 -day period. ${ }^{13}$

\section{Mifepristone}

This is an antiprogesterone agent that is effective for EC. However, mifepristone is not available in many countries, and has been mainly used in the People's Republic of China as EC. The oral dose is 10 or $50 \mathrm{mg}$, and is effective up to 5 days after contraceptive failure. Efficacy does not decline over time. ${ }^{14}$ It acts by preventing or delaying ovulation in 
a dose-dependent fashion. ${ }^{14}$ It is not commonly used, due to cost and accessibility. Access to mifepristone is highly regulated in the US.

\section{Levonorgestrel}

This is the most widely available form of EC worldwide, and is available over the counter in several countries. LNG as EC is a $1.5 \mathrm{mg}$ dose, given as soon as possible after contraceptive failure or unprotected sex. Although it is effective for up to 5 days (120 hours) after contraceptive failure, its efficacy declines over time. It works by preventing or delaying ovulation, and works only up to the luteinizing hormone surge. ${ }^{14}$

\section{Yuzpe regimen}

This consists of $100 \mu \mathrm{g}$ ethinyl estradiol and $1 \mathrm{mg}$ norgestrel, given as two doses 12 hours apart. It is effective for up to 5 days, but efficacy declines over time. It works by preventing or delaying ovulation. It has the lowest efficacy of all the EC methods. ${ }^{11}$

\section{Contraindications for oral EC}

The most common contraindications for oral EC are ongoing pregnancy (not because of teratogenicity, but simply because if one is pregnant, there is no need for these medications), hypersensitivity to any product component, and undiagnosed abnormal vaginal bleeding.

\section{Weight and efficacy}

The efficacy of all oral EC is decreased in obese women, although obesity is not a contraindication for EC. One study reported that the failure rate of $\mathrm{LNG}(5.8 \%)$ was greater than that for UPA $(2.6 \%)$ in obese women. ${ }^{15}$ For women with a body mass index (BMI) of 26 or over who used progestinonly EC, pregnancy rates were no different than would be expected if they had not used EC at all. UPA appeared to lose effectiveness at a BMI threshold of $35 .{ }^{15,16}$ In contrast, the efficacy of the copper IUD as EC is unaffected by weight. For women who have a BMI of 26 or greater, if the copper IUD is unavailable for EC, UPA should be considered as the second-best available option over LNG. ${ }^{15}$

\section{Key social determinants affecting knowledge and use of EC}

We propose an evidence-based ecological model (Figure 1), accounting for proximal and distal factors at the levels of national/public policy, community/institutional, provider/ clinic, interpersonal, and intrapersonal factors. While an ecological model most comprehensively illustrates the complexity of adolescent knowledge and use of EC, limitations exist. The chosen categories do not necessarily represent all possible factors, and there may be overlap both within and among different categories. Proximal factors may receive more attention than warranted, because they are more easily detected. Both causal and noncausal predisposing factors may not be clearly delineated. Nevertheless, an ecological model enables us to address multiple layers of causal and predisposing risk, while adapting to EC knowledge and use.

\section{Intrapersonal-level factors}

Studies have shown that older teens are more likely to have an awareness of EC. One of the reasons could be that older teens are likely to be more sexually active than younger teens. ${ }^{17,18}$ Sex differences in knowledge have been found in the US and other countries. In a 2015 study, young women (86\%) reported higher rates of "hearing about emergency contraception" than young men (70\%). ${ }^{18}$ Another study of 278 Turkish male university students showed that only $14.5 \%$ had heard about EC. ${ }^{19}$ EC awareness was measured among 11,392 women aged 15-44 years using data from the 2003 CA Health Interview Survey. ${ }^{20}$ They found that awareness was lower among teens, women of color, poor women, those with publicly funded insurance, those without a usual source of care, immigrants, non-English-speaking, and rural residents. ${ }^{20}$ Lack of insurance is a major barrier in receiving preventive reproductive care in a timely manner, and thus uninsured adolescents are at greater risk of pregnancy. ${ }^{21,22}$ One study of homeless, uninsured, and/or high-risk adolescents reported high rates of EC-pill awareness $(70 \%-86 \%)$, but significant gaps in knowledge of mechanism, access, and proper use of EC pills. ${ }^{18}$ One study showed that adolescents generally lacked sufficient knowledge about what EC is and its mechanism of action. ${ }^{17}$

Minority urban adolescents had several misconceptions about EC pills, as well as concerns about confidentiality, and were highly influenced by opinions of family and friends close to them. ${ }^{23}$ Another study showed that familiarity with EC, having a new sex partner, having unprotected sex at least once, having negative feelings toward pregnancy, and using condoms as one's main contraceptive method, were all positively associated with likelihood of recent EC use. ${ }^{24}$ Language barriers can decrease use of EC. In a study in California, where researchers posed as English versus Spanish callers called a pharmacy to obtain EC, Spanish callers were less successful in obtaining EC. ${ }^{25}$ In a Nicaraguan study, women who used EC were younger, had lower parity and had higher education and socioeconomic status than those who were not using EC. ${ }^{26}$ In a cross-sectional study at Rhode Island, women 


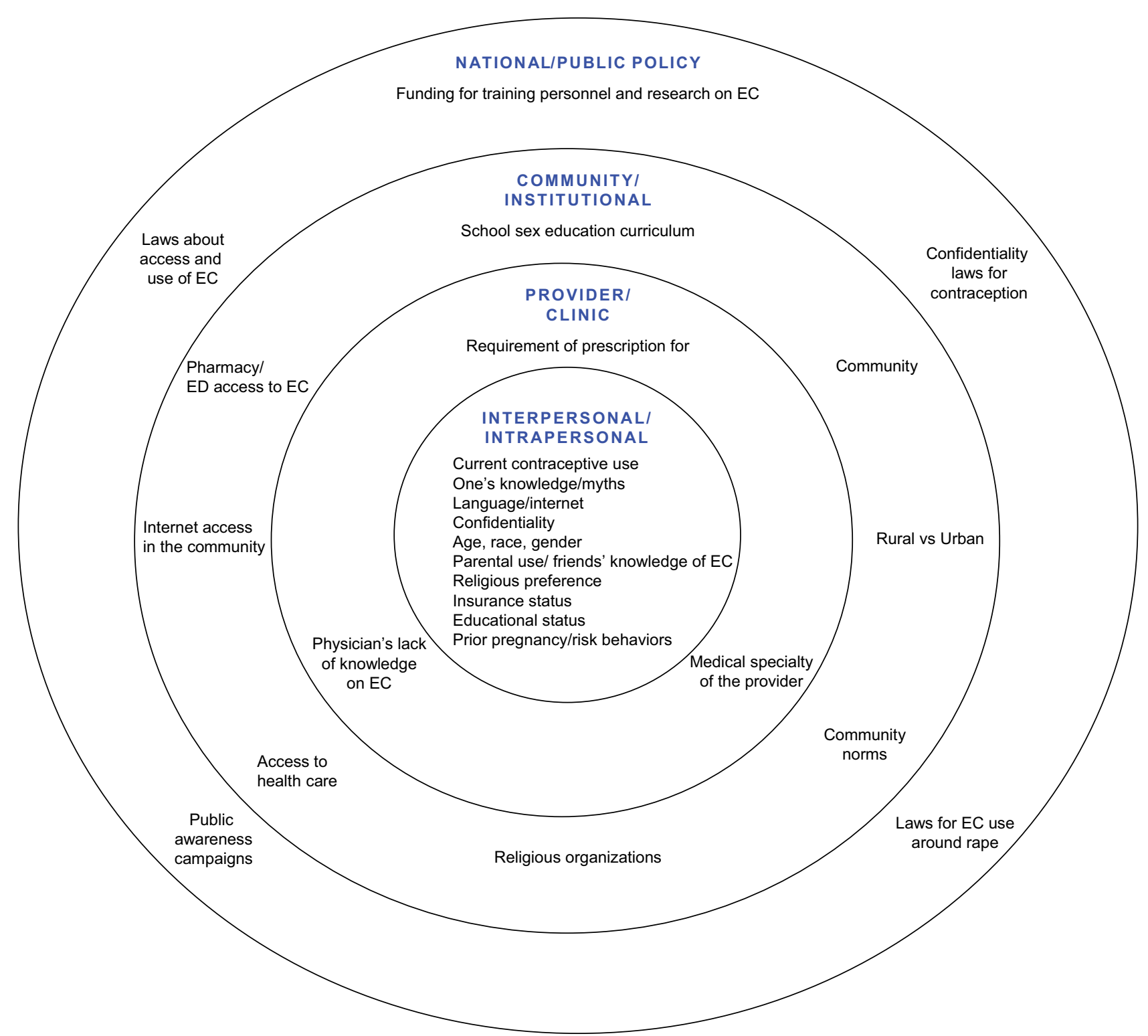

Figure I A socioecological model looking at the factors influencing knowledge and use of emergency contraception (EC)

Abbreviation: ED, emergency department.

who used EC were more likely to have a higher educational status, be single, have had unprotected last intercourse, and less likely to have had a sexually transmitted infection (STI). ${ }^{27}$

Research shows increased likelihood of EC use in adolescents with school and/or home access to the internet. These adolescents are likely to use the internet to access information about EC and a location from which to obtain EC. ${ }^{28}$ In a randomized controlled trial, access to computer assisted provision of EC in waiting rooms in urgent care clinics increased knowledge of EC in a state where EC had been available without a prescription for 3 years. ${ }^{29}$ In a Finnish study, smoking, dating, poor school achievement, and not living in a nuclear family, were all associated with increased EC use. ${ }^{30}$

\section{Interpersonal-level factors}

A 2016 cross-sectional study of students 15-19 years old in Brazil showed that knowledge of EC was not associated with its use, but knowing someone that had used the method increased its use. ${ }^{31}$ It was also found that peer-group conversations on EC had greater influence on the use of EC than knowledge itself, economic status, or sexual experience. ${ }^{31}$ Adolescents with higher levels of parental monitoring had lower rates of EC use. ${ }^{32}$

\section{Provider/clinic-level factors}

A 1999 study found that only $17 \%$ of pediatricians routinely counseled about EC. ${ }^{33}$ Female pediatricians were more likely to do so, but $73 \%$ of respondents could not identify any of 
the US Food and Drug Administration (FDA)-approved methods of EC. ${ }^{33}$ A 2016 study showed that the type of specialty of the provider and the proportion of women of reproductive age in the practice were related to knowledge and provision of some forms of EC. Among the reproductive health specialists, $81 \%$ provided LNG EC in their practice, although only half $(52 \%)$ had heard of UPA and very few had provided it (14\%). The more effective methods of EC, such as UPA and the copper IUD, were little known and had rarely been provided outside reproductive health specialties. ${ }^{34}$ In one study, women preferred to talk with their physicians and get a prescription for EC compared to nonprescription access to EC. ${ }^{32}$

\section{Community/institutional-level factors}

One study showed that adolescents who lived in rural areas, had transportation issues, or lacked access to pharmacies had lower levels of EC use. ${ }^{18}$ A 2009 study of inner-city adolescents in New York City found low levels of EC knowledge: only $30 \%$ of the sexually experienced adolescents had heard of EC. ${ }^{35}$ Nevertheless, once they found out about it, the vast majority $(87 \%)$ professed an intent to try the method if the need arose. ${ }^{35}$ Community access to family-planning clinics increased odds of using EC. ${ }^{36}$

\section{National/public policy-level factors}

Encompassing all these determinants for adolescent knowledge and use of EC are policies that national groups and governments have put in place to improve access to EC in adolescents. Even with these policies, many adolescents are still not aware of or lack knowledge about the proper use of EC. EC awareness increased after a public-awareness campaign in Scotland. ${ }^{37}$ Princeton University has hosted a website dedicated to EC since 1996. The Emergency Contraception website is operated by the Office of Population Research at Princeton University and by the Association of Reproductive Health Professionals (http://ec.princeton.edu).

Adolescent use of EC significantly increased in the US from $8 \%$ in 2002 to $22 \%$ in $2011-2013 .{ }^{38}$ A study from British Columbia showed cost savings with increased availability of EC as a nonprescription medication. ${ }^{39}$ In April 2013, the FDA approved Plan B One-Step for use, without a patient needing a prescription and without age restrictions. UPA (Ella) can be purchased through online websites (eg, www. ella-kwikmed.com, www.prjktruby.com), which provide a medical prescription and deliver the medication. An increase in the cost of over-the-counter LNG EC in the US from about $\$ 25$ to about $\$ 45$ and lack of health insurance in many patients made it difficult for patients to buy these products. ${ }^{40}$ Under the US's 2010 Affordable Care Act, most insurers must cover all FDA-approved birth control for women, including over-the-counter contraceptive medications, such as EC. Similar legislation in other countries can improve access to and knowledge of EC. ${ }^{40}$

\section{Best practices for overcoming barriers to knowledge about and use of EC}

In order to making a significant impact and improve knowledge and use of EC, there need to be comprehensive adolescent-focused programs that will 1) help assess knowledge of EC at the individual level, 2) improve use by making it readily available in a confidential manner, 3 ) increase over-the-counter and pharmacy access, 4) implement educational programs at the community or school level, and 5) have national policies that will reduce cost and improve access and availability of EC products readily for all adolescents. Programs should involve all relevant stakeholders, and have broad aims to influence social and cultural norms and laws and policies that affect the adolescent's right to accurate knowledge on sexual and reproductive health.

\section{Principles of intervention}

Intervention should necessitate multisector involvement: this means simultaneously involving all stake holders in program planning, implementation, and outcome evaluations. ${ }^{41}$ Stakeholders range from individuals to global organizations, and include adolescents and young adults, parents, extended family, siblings, teachers, school administrators, health care providers, clinic nurses and staff, staff of hospitals, community outreach programs, social workers, local community leaders, religious institutions, politicians and policy makers, and international organizations like the United Nations, the United States Agency for International Development, and the World Health Organization. Intervention needs to occur early in adolescence to promote healthy behavior patterns. ${ }^{41}$ Both adolescent risk and protective factors should be targeted. Risk and protective factors develop during varying stages of adolescence. While some of these are problem-specific, many are general factors that predict multiple outcomes, such as adolescent pregnancy, substance abuse, poor school performance, violence, crime, and mental illness. Given the commonality of these risk factors across 
adolescent-behavior issues, targeting one risk factor will impact multiple problems.

\section{Proposed interventions to improve knowledge of EC}

In the following sections, we present interventions at the provider/clinic level, community level, and national/public policy level to help improve knowledge and use of EC, based on the ecological model in the Supplementary materials. Intervention at any of these levels in the model will have an impact on the other levels, especially at the individual level.

\section{Provider/clinic-level interventions}

Goals are to assess knowledge, provide confidential youthfriendly clinic services, and improve the delivery of EC.

\section{Potential strategies to assess knowledge of EC}

Providers and clinics can use self-administered, anonymous surveys (example in Table 1) in order to assess knowledge of ECs and understand major misconceptions. Surveys are easy and convenient for both patients and providers. Analysis of the survey results can help providers determine the gaps and address them in an effective and efficient manner.

\section{Potential strategies to dispel any myths or misinformation about EC}

Survey patients about their knowledge and review the answers. Ask patients what do they know about EC, why would they not want to use it, and/or why might they want to use it.

\section{Potential strategies to improve access to and delivery of EC to adolescents}

One of the most important interventions would be to discuss EC with any adolescent who comes in for an annual preventive care visit and/or a reproductive health care visit. This helps set the stage for when and if the need arises. The following represent various types of models of delivery of health care to adolescents.

\section{Specialized adolescent clinics}

These clinics are usually affiliated with a hospital and/or university. These also serve as referral centers for nearby health facilities and provide academic and research training for physicians. They can serve as the patient-centered medical home (PCMH) ${ }^{42}$ and according to the American Academy of Pediatrics, the PCMH model is a way to ensure continuity of care from birth to young adulthood and to provide coordinated health care among specialist and related service providers. ${ }^{43}$ There are seven identified characteristics of the PCMH model: care that is accessible, continuous, comprehensive, family-centered, coordinated, compassionate, and culturally effective ${ }^{43}$ While increasing care coordination and enhancing overall quality, this model also simultaneously reduces costs. Key to PCMH success are health information technology, such as the use of electronic medical records, and payment reform as outlined by the 2010 Patient Protection and Affordable

Table I Survey

\begin{tabular}{|c|c|c|c|c|}
\hline EC questions & Answer choices & (points given) & & \\
\hline $\begin{array}{l}\text { I. Have you ever heard of EC (also called } \\
\text { "morning-after pill" or "plan B")? }\end{array}$ & Yes (I) & No $(0)$ & & Uncertain (0) \\
\hline 2. Is EC an abortion pill? & Yes $(1)$ & No $(0)$ & & Uncertain (0) \\
\hline 3. Can you legally get confidential EC? & Yes ( 1 ) & No $(0)$ & & Uncertain (0) \\
\hline 4. In certain situations, can you obtain EC over the counter? & Yes ( 1 ) & No $(0)$ & & Uncertain (0) \\
\hline 5. Can males legally get EC for future use by a female partner? & Yes (I) & No $(0)$ & & Uncertain $(0)$ \\
\hline 6. How effective is EC in preventing an unintended pregnancy? ${ }^{\text {a }}$ & $90 \%(1)$ & $80 \%(I)$ & $60 \%(0)$ & $50 \%(0)$ \\
\hline $\begin{array}{l}\text { 7. Which is a possible side effect of EC (choose all } \\
\text { that are true) } \text { ? }^{\text {b }}\end{array}$ & Infertility $(0)$ & $\begin{array}{l}\text { Menstrual } \\
\text { irregularities }(0.5)\end{array}$ & Weight gain (0) & Vomiting $(0.5)$ \\
\hline $\begin{array}{l}\text { 8. Can EC be used as a regular form of family } \\
\text { planning like the birth-control pill? }\end{array}$ & Yes $(0)$ & No $(1)$ & & Uncertain (0) \\
\hline 9. Can plan B prevent sexually transmitted infections? & Yes $(0)$ & No (I) & & Uncertain (0) \\
\hline $\begin{array}{l}\text { 10. Plan B should be taken within what time period of } \\
\text { unprotected sex? }\end{array}$ & Within 7 days $(0)$ & Within 5 days (I) & Within 3 days $(I)$ & Within I day $(0)$ \\
\hline
\end{tabular}

Notes: Adapted from J Pediatr Adolesc Gynecol, 28(5). Yen S, Parmar DD, Lin EL, Ammerman S. Emergency contraception pill awareness and knowledge in uninsured adolescents: high rates of misconceptions concerning indications for use, side effects, and access. 337-342, Copyright (2015), with permission from Elsevier. ${ }^{18}$ Introductory text: "This survey contains 10 questions regarding EC awareness, knowledge, and access. It takes approximately 5 minutes to complete. All the questions are multiple choice, and 7 of the 10 questions require simply 'yes, no, or uncertain' responses. To score the surveys, each correct answer is given a value of $\mathrm{I}$, except for question 7 , for which each correct answer is 0.5 . A perfect score would total 10 points. Each question is scored correct/incorrect, and the final score is summed for each survey." alf multiple answers were circled to include either 90 or 80 , I point was awarded; bif multiple answers were circled to include menstrual irregularities or vomiting, 0.5 point was awarded for each; cif multiple answers were circled to include 3 or 5 days, I point was awarded.

Abbreviation: EC, emergency contraception. 
Care Act. Access to a PCMH can help providers deliver highquality medical care, including contraception counseling, and provide EC to help prevent unintended pregnancies.

\section{Community-based health care facilities}

These facilities can be either a stand-alone or government-run institution, and can be an integral part of a district or a county health system. They can be focused family-planning clinics, such as Planned Parenthood, or a general practice. ${ }^{44,45}$ They can also serve as PCMHs for care of adolescents.

\section{School-based or college-based health services}

These clinics are linked with schools or colleges, and provide health services for those who study or live close to the schools and colleges. ${ }^{46}$ School-based health centers (SBHCs) serve an essential role in providing access to high-quality, comprehensive care to underserved adolescents in many schools across the US. ${ }^{47}$ They can be an efficient and important delivery medium for information on EC. The American Academy of Pediatrics recognizes the proven benefits and exciting potential of SBHCs. Traditional SBHCs are located in urban areas and schools with large student populations. In order to reach rural areas and schools with lower numbers of students, telehealth SBHCs (tSBHCs) are now being utilized. These tSBHCs provide sexual and reproductive services through telemedicine, and operate in communities where geographic barriers and financial challenges have prevented the establishment of SBHCs. tSBHCs are an important part of the PCMH model to help improve access to and use of EC.

\section{Community-based centers}

Some community centers provide health services in addition to educational and recreational services. These centers can be the starting point for health care for adolescents; they often have links with health facilities nearby, where adolescents and young people can be referred..$^{44,48}$

\section{Pharmacies}

Most pharmacies around the world sell contraceptive products, such as condoms and EC, and some also provide clinic services.

\section{Outreach programs, such as mobile clinics}

Mobile health clinics have been able to provide comprehensive health services, including contraceptive services, by leveraging their mobility to treat people in the convenience of their own communities. They are particularly able to serve at-risk marginalized populations who have trouble navigating the health care system, who lack health insurance, or who live in rural environments with poor health care access. ${ }^{49-51}$ "Teen health vans" park in the heart of the community in familiar spaces, like shopping centers, recreation centers, or at or near schools, which lends themselves to the local community atmosphere. Of note, mobile clinics successfully attract young men, who tend to have poorer health-seeking behavior, ${ }^{41}$ thus helping providers educate young males regarding safe sexual practices, use of condoms, and prevention of unintended pregnancies.

\section{Potential strategies to provide confidential, youth- friendly clinic services}

Research has shown that the main reasons for health services not reaching adolescents are lack of availability of youthfriendly services, complicated by cultural, access, and cost issues. ${ }^{52}$ Access to health care services is an important component for prevention of teenage pregnancies. Research in the last two decades, conducted in both developed and developing countries, has focused on the barriers that adolescents face in accessing health services. ${ }^{52}$ This research has pointed out clearly that youth need services that are sensitive to their unique developmental stage. As per Pathfinder International: "Health services are understood to be youth friendly if they have policies and attributes that attract youth to the facility or program, provide a comfortable and appropriate setting for youth, meet the needs of young people, and are able to retain their youth clientele for follow-up and repeat visits". ${ }^{53}$ Barriers to youthfriendly services to deliver EC or any form of contraception relate to restrictive policies, access, cost of care, and acceptability issues. ${ }^{52}$ Lack of confidentiality and fear of parents finding out or parents' reaction(s) are very significant barriers in developing countries. In order to overcome these barriers, principles derived from the World Health Organization Quality Assessment Guidebook ${ }^{54}$ (Supplementary materials) must be incorporated into the services, which are as follows:

- equitable - all adolescents, not just certain groups, are able to obtain the health services

- accessible - adolescents are able to obtain the services that are provided

- acceptable - services are provided to meet the expectations of adolescent clients

- appropriate - the health services that adolescents need are provided

- effective - services are provided in the right way, and make a positive contribution to the health of adolescents.

These interventions can be incorporated in the various types of clinic services described earlier. Relevant technologies, including websites, social media, and mobile phones, should be utilized to help with implementation of programs, customized to the area being targeted. 


\section{Community/school-level interventions}

Reproductive and sexual health-education programs at schools can play an important role in educating adolescents about different types of contraception, including EC. It is the basic right of each adolescent to know about EC, in addition to comprehensive sex education that teaches them about bodily functions, puberty, sex, reproduction, safe sex, and contraceptive practices. If the adolescents are not informed of these, they will likely make poor choices about their sexual health and put themselves at risk for early and unintended pregnancies and STIs. Therefore, a comprehensive, medically accurate, age-appropriate curriculum should be developed to educate adolescents regarding their sexual and reproductive health. These curricula can be incorporated into schools at a state and national level. Adolescents must be educated on basic structure and function of the reproductive system, puberty, the menstrual cycle, menstrual hygiene, sex and safe-sex practices, contraception including EC, sexually transmitted diseases, nutrition, protection from sexual abuse and rape, and the availability of youth-friendly services. A review of 83 sexuality-education programs, 18 of them in developing countries, showed that sex-education programs can significantly (by two-thirds) reduce risky sexual behavior in young people. ${ }^{55} \mathrm{~A}$ review in sub-Saharan Africa showed that school-based sex-education programs do make a significant improvement in the knowledge, intentions, and attitudes of adolescents. ${ }^{56}$ Similar programs in Thailand improved knowledge, and adolescents were more likely to intend to refuse sex and decrease frequency of sex, although there was no change in condom use. ${ }^{57}$ One review highlighted 17 characteristics for the effectiveness of such programs, which are related to program development, content, and implementation..$^{58}$ These can be incorporated to improve adolescent knowledge of EC (Table 2).

\section{National-level interventions}

\section{Public service announcements/campaigns}

In the US in 2011, the National Campaign to Prevent Teen and Unplanned Pregnancy joined the Ad Council (a collaboration of major advertising firms) to debut a groundbreaking, firstever national multimedia public service campaign designed to reduce the rates of unplanned pregnancies. The campaign directed adolescents and young adults to bedsider.org, a comprehensive, online, youth-friendly program on contraceptive methods, which became a national success. This program is still recommended to adolescents and young adults to learn about contraception.

\section{Television shows}

TV shows can be a very effective method to reach large audiences about contraception. One such example is comedian Aziz Ansari's popular show called Master of None on Netflix, where "plan B" makes for great comedy in his opening episode. Another example is the show East Los High on the

Table 2 Characteristics of effective sex-education programs

\section{Curriculum development}

- involved people with different backgrounds in theory, research, and sex education

- planned specified health goals and identified behaviors affecting those goals; addressed risk and protective factors affecting those behaviors; and developed activities to address those factors

- assessed relevant needs and assets of target group

- designed activities consistent with community values and available resources, eg, staff skills, staff time, space, supplies

- pilot-tested curriculum activities

Content of curriculum

- created a safe social environment for youth participants

- focused on at least one of three health goals: prevention of HIV, sexually transmitted infections, unintended pregnancy

- focused narrowly on specific sexual behaviors that lead to these health goals (eg, abstaining from sex, using condoms); gave clear messages about these behaviors; addressed how to avoid situations that might lead to these behaviors

- targeted several psychosocial risk and protective factors affecting these behaviors (eg, knowledge, perceived risks, attitudes, perceived norms, selfefficacy)

- included multiple activities to change each of the targeted risk and protective factors

- used teaching methods that actively involved youth participants, and helped them to personalize the information

- made use of activities appropriate to the young people's culture, developmental level, and previous sexual experience

- addressed topics in a logical order

Curriculum implementation

- selected educators with desired characteristics, and provided training in curriculum

- secured at least minimum support from appropriate authorities (eg, ministry of health, school district, community organization)

- if needed, implemented activities to recruit youth and overcome barriers to their involvement in program

- implemented virtually all curriculum activities with fidelity

Note: Adapted from World Health Organ Tech Rep Ser, 938, Kirby D, Obasi A, Laris BA, The effectiveness of sex education and HIV education interventions in schools in developing countries, 103-150, discussion 317-341. Copyright (2006). Available from: https://www.ncbi.nlm.nih.gov/pubmed/16921919. Accessed November 2, 2016. ${ }^{58}$ 
Hulu network, which is popular among youth and Latinos. One episode included a youth who needed EC, and the episode stealthily incorporated EC-education points in its programming.

\section{Legislation}

Policies that will enable the following will increase awareness and use of EC:

- making sure that ECs are available over the counter to any age and sex

- protect adolescents' rights to confidential reproductive health care services that will allow access to EC

- ensure that EC is covered by insurance.

One such example would be California's Family PACT (Family Planning, Access, Care, and Treatment) program. It is an innovative method of providing free, comprehensive, and confidential family-planning services to low-income adolescent and adult females and males.

\section{Evaluation of interventions Outcomes and relevant indicators to be evaluated}

All of the interventions and their components listed can be considered for evaluation, including feasibility and cultural sensitivity, focusing on increase in knowledge and use of EC.

\section{Method of evaluation}

Pre- and postintervention studies using specific indicators can be performed. Table 3 provides a comprehensive list of indicators that can potentially be utilized for these kinds of studies. Other methods, such as focus groups and in-depth interviews, can also be performed. Randomized controlled trials using external evaluators would be the best method, which should be incorporated if financial resources are available.

\section{Conclusion}

Young people are the inheritors of our future. Young people are not the sources of problems - they are the resources that are needed to solve them. They are not expenses, but rather investments: not just young people, but citizens of the world, present as well as the future. ${ }^{59}$

Adolescents have the right to lead healthy lives. They can do so when they are informed and given access to confidential and safe family-planning services, including information about EC, even before they become sexually active. This
Table 3 Indicators for pre- and postintervention studies
Education Improved school enrollment, school retention, especially from primary to secondary schools, school attainment, improved school connectedness

Indicator Adolescents are enrolled in school; improved attendance and school completion

Health Improved use of physical and mental health, reproductive health services, contraception, reduction of anemia, improved child/adolescent nutrition, increased height and weight of young children Indicator Teens have ageappropriate weight and height, adopt health-enhancing behaviors, avoid health-compromising behaviors

Reproductive outcomes Decrease in teen-pregnancy rates, decrease in early child marriages, improved spacing of pregnancies, delayed first pregnancy

Indicator Median age at marriage, median age at first child, rate of adolescent pregnancies, rate of abortions in adolescents, decrease in maternal and infant mortality rates
Self-efficacy Teens have positive sense of self, so that they can impact their own life and environment around them; improved life skills and decisionmaking skills

Indicator Demonstrate optimism, confidence, and/or sense of self-control Teens are surrounded by role models whom they can emulate Indicator Reports one significant adult in their lives

Physical and emotional maturity Absence of bullying, violence, and abuse at home, in schools, and in the community Indicator Reports feeling safe at home and school and in community Social network of support

will help them lead healthier lives, prevent unintended pregnancies, and in turn will help them lead more productive lives. This will ultimately help the enhancement of a country's economy, reduce poverty, and increase educational attainment.

\section{Disclosure}

The authors report no conflicts of interest in this work.

\section{References}

1. World Health Organization. Adolescent pregnancy. 2014. Available from: http://www.who.int/mediacentre/factsheets/fs364/en. Accessed August 10, 2016.

2. Sedgh G, Finer LB, Bankole A, Eilers MA, Singh S. Adolescent pregnancy, birth, and abortion rates across countries: levels and recent trends. J Adolesc Health. 2015;56(2):223-230.

3. Hoffman SD, Maynard RA. Kids Having kids: Economic Costs and Social Consequences of Teen Pregnancy. 2nd ed. Washington: Urban Institute Press; 2008.

4. Palermo T, Bleck J, Westley E. Knowledge and use of emergency contraception: a multicountry analysis. Int Perspect Sex Reprod Health. 2014;40(2):79-86.

5. Barot S. Past due: emergency contraception in U.S. reproductive health programs overseas. Guttmacher Policy Rev. 2010;13(2):8-11. 
6. American Society for Emergency Contraception. Inching towards progress: ASEC's 2015 Pharmacy Access Study. 2015. Available from: http://americansocietyforec.org/uploads/3/2/7/0/3270267/asec_2015_ ec_access_report_1.pdf. Accessed August 10, 2016 .

7. Cleland K, Zhu H, Goldstuck N, Cheng L, Trussell J. The efficacy of intrauterine devices for emergency contraception: a systematic review of 35 years of experience. Hum Reprod. 2012;27(7):1994-2000.

8. Turok DK, Godfrey EM, Wojdyla D, Dermish A, Torres L, Wu SC. Copper T380 intrauterine device for emergency contraception: highly effective at any time in the menstrual cycle. Hum Reprod. 2013;28(10): 2672-2676.

9. World Health Organization. Selected Practice Recommendations for Contraceptive Use. 2nd ed. Geneva: WHO; 2004.

10. World Health Organization. Emergency contraception. 2016. Available from: http://who.int/mediacentre/factsheets/fs244/en. Accessed August $10,2016$.

11. Society for Adolescent Health and Medicine. Emergency contraception for adolescents and young adults: guidance for health care professionals. J Adolesc Health. 2016;58(2):245-248.

12. Brache V, Cochon L, Jesam C, et al. Immediate pre-ovulatory administration of $30 \mathrm{mg}$ ulipristal acetate significantly delays follicular rupture. Hum Reprod. 2010;25(9):2256-2263.

13. Glasier AF, Cameron ST, Fine PM, et al. Ulipristal acetate versus levonorgestrel for emergency contraception: a randomised non-inferiority trial and meta-analysis. Lancet. 2010;375(9714):555-562.

14. Gemzell-Danielsson K, Berger C, Lalitkumar PG. Mechanisms of action of oral emergency contraception. Gynecol Endocrinol. 2014;30(10):685-687.

15. Glasier A, Cameron ST, Blithe D, et al. Can we identify women at risk of pregnancy despite using emergency contraception? Data from randomized trials of ulipristal acetate and levonorgestrel. Contraception. 2011;84(4):363-367.

16. Moreau C, Trussell J. Results from pooled phase III studies of ulipristal acetate for emergency contraception. Contraception. 2012;86(6): 673-680.

17. Ahern R, Frattarelli LA, Delto J, Kaneshiro B. Knowledge and awareness of emergency contraception in adolescents. J Pediatr Adolesc Gynecol. 2010;23(5):273-278.

18. Yen S, Parmar DD, Lin EL, Ammerman S. Emergency contraception pill awareness and knowledge in uninsured adolescents: high rates of misconceptions concerning indications for use, side effects, and access. J Pediatr Adolesc Gynecol. 2015;28(5):337-342.

19. Sahin NH. Male university students' views, attitudes and behaviors towards family planning and emergency contraception in Turkey. J Obstet Gynaecol Res. 2008;34(3):392-398.

20. Baldwin SB, Solorio R, Washington DL, Yu H, Huang YC, Brown ER. Who is using emergency contraception? Awareness and use of emergency contraception among California women and teens. Womens Health Issues. 2008;18(5):360-368.

21. Callahan ST, Cooper WO. Uninsurance and health care access among young adults in the United States. Pediatrics. 2005;116(1): $88-95$.

22. Irwin CE Jr, Adams SH, Park MJ, Newacheck PW. Preventive care for adolescents: few get visits and fewer get services. Pediatrics. 2009; 123(4):e565-e572.

23. Mollen CJ, Barg FK, Hayes KL, Gotcsik M, Blades NM, Schwarz DF. Assessing attitudes about emergency contraception among urban, minority adolescent girls: an in-depth interview study. Pediatrics. 2008;122(2): $395-\mathrm{e} 401$

24. Whittaker PG, Berger M, Armstrong KA, Felice TL, Adams J. Characteristics associated with emergency contraception use by family planning patients: a prospective cohort study. Perspect Sex Reprod Health. 2007;39(3):158-166.

25. Sampson O, Navarro SK, Khan A, et al. Barriers to adolescents' getting emergency contraception through pharmacy access in California: differences by language and region. Perspect Sex Reprod Health. 2009;41(2):110-118.
26. Salazar M, Ohman A. Who is using the morning-after pill? Inequalities in emergency contraception use among ever partnered Nicaraguan women: findings from a national survey. Int J Equity Health. 2014; 13:61.

27. Phipps MG, Matteson KA, Fernandez GE, Chiaverini L, Weitzen S. Characteristics of women who seek emergency contraception and family planning services. Am J Obstet Gynecol. 2008;199(2):111 e111-e115.

28. Halpern CT, Mitchell EM, Farhat T, Bardsley P. Effectiveness of webbased education on Kenyan and Brazilian adolescents' knowledge about HIV/AIDS, abortion law, and emergency contraception: findings from TeenWeb. Soc Sci Med. 2008;67(4):628-637.

29. Schwarz EB, Gerbert B, Gonzales R. Computer-assisted provision of emergency contraception: a randomized controlled trial. J Gen Intern Med. 2008;23(6):794-799.

30. Falah-Hassani K, Kosunen E, Shiri R, Rimpela A. Emergency contraception among Finnish adolescents: awareness, use and the effect of non-prescription status. BMC Public Health. 2007;7:201.

31. Chofakian CB, Borges AL, Sato AP, Alencar GP, Santos OA, Fujimori E. Does the knowledge of emergency contraception affect its use among high school adolescents? Cad Saude Publica. 2016;32(1):e00188214.

32. Wu J, Gipson T, Chin N, et al. Women seeking emergency contraceptive pills by using the internet. Obstet Gynecol. 2007;110(1):44-52 .

33. Golden NH, Seigel WM, Fisher M, et al. Emergency contraception: pediatricians' knowledge, attitudes, and opinions. Pediatrics. 2001;107(2):287-292.

34. Batur P, Cleland K, McNamara M, Wu J, Pickle S. Emergency contraception: a multispecialty survey of clinician knowledge and practices. Contraception. 2016;93(2):145-152.

35. Gilliam ML, Davis SD, Neustadt AB, Levey EJ. Contraceptive attitudes among inner-city African American female adolescents: barriers to effective hormonal contraceptive use. J Pediatr Adolesc Gynecol. 2009;22(2):97-104.

36. Raymond EG, Trussell J, Polis CB. Population effect of increased access to emergency contraceptive pills: a systematic review. Obstet Gynecol. 2007;109(1):181-188.

37. Fitter M, Urquhart R. Awareness of emergency contraception: a followup report. J Fam Plann Reprod Health Care. 2008;34(2):111-113.

38. Daniels K, Jones J, Abma J. Use of emergency contraception among women, aged 15-44: United States, 2006-2010. NCHS Data Brief. 2013;(112):1-8

39. Soon JA, Meckley LM, Levine M, Marciante KD, Fielding DW, Ensom MH. Modelling costs and outcomes of expanded availability of emergency contraceptive use in British Columbia. Can J Clin Pharmacol. 2007;14(3):e326-e338.

40. Trussell J, Raymond EG, Cleland K. Emergency Contraception: A Last Chance to Prevent Unintended Pregnancy. Princeton (NJ) Princeton University; 2016.

41. Catalano RF, Fagan AA, Gavin LE, et al. Worldwide application of prevention science in adolescent health. Lancet. 2012;379(9826):1653-1664.

42. [No authors listed]. Who is responsible for adolescent health? Lancet. 2004;363(9426):2009.

43. Strickland B, McPherson M, Weissman G, van Dyck P, Huang ZJ, Newacheck P. Access to the medical home: results of the National Survey of Children with Special Health Care Needs. Pediatrics. 2004;113(5 Suppl): $1485-1492$.

44. Kang M, Bernard D, Usherwood T, et al. Better Practice in Youth Health: Final Report on Research Study Access to Health Care among Young People in New South Wales - Phase 2. Sydney: University of Sydney; 2005.

45. Toomet K, Part K, Haldre K. A decade of youth clinics in Estonia. Entre Nous Cph Den. 2004;58:5-6.

46. Brindis CD, Klein J, Schlitt J, Santelli J, Juszczak L, Nystrom RJ. School-based health centers: accessibility and accountability. J Adolesc Health. 2003;32(6 Suppl):98-107.

47. North SW, McElligot J, Douglas G, Martin A. Improving access to care through the patient-centered medical home. Pediatr Ann. 2014; 43(2):e33-e38. 
48. World Health Organization. Adolescent Friendly Health Services: An Agenda for Change. Geneva: WHO; 2002.

49. Mayernik D, Resick LK, Skomo ML, Mandock K. Parish nurse-initiated interdisciplinary mobile health care delivery project. J Obstet Gynecol Neonatal Nurs. 2010;39(2):227-234.

50. Hill C, Zurakowski D, Bennet J, et al. Knowledgeable Neighbors: a mobile clinic model for disease prevention and screening in underserved communities. Am J Public Health. 2012;102(3):406-410.

51. Edgerley LP, El-Sayed YY, Druzin ML, Kiernan M, Daniels KI. Use of a community mobile health van to increase early access to prenatal care. Matern Child Health J. 2007;11(3):235-239.

52. Tylee A, Haller DM, Graham T, Churchill R, Sanci LA. Youth-friendly primary-care services: how are we doing and what more needs to be done? Lancet. 2007;369(9572):1565-1573.

53. Pathfinder International. Making Reproductive Health Services Youth Friendly. Washington: Focus on Young Adults; 1999.

54. World Health Organization. Quality Assessment Guidebook: A Guide to Assessing Health Services for Adolescent Clients. Geneva: WHO; 2009.
55. Bearinger LH, Sieving RE, Ferguson J, Sharma V. Global perspectives on the sexual and reproductive health of adolescents: patterns, prevention, and potential. Lancet. 2007;369(9568):1220-1231.

56. Paul-Ebhohimhen VA, Poobalan A, van Teijlingen ER. A systematic review of school-based sexual health interventions to prevent STI/HIV in sub-Saharan Africa. BMC Public Health. 2008;8:4.

57. Thato R, Jenkins RA, Dusitsin N. Effects of the culturally-sensitive comprehensive sex education programme among Thai secondary school students. J Adv Nurs. 2008;62(4):457-469.

58. Kirby D, Obasi A, Laris BA. The effectiveness of sex education and HIV education interventions in schools in developing countries. World Health Organ Tech Rep Ser. 2006;938:103-150; discussion 317-341.

59. United Nations. A WORLD FIT FOR US- Message from the Children's Forum, delivered to the UN General Assembly Special Session on Children by child delegates, Gabriela Azurduy Arrieta, 13, from Bolivia and Audrey Cheynut, 17, from Monaco on 8 May 2002. Available from: https://www.unicef.org/specialsession/documentation/childrensstatement.htm. Accessed November 16, 2016. 


\section{Supplementary materials}

\section{Proposed interventions to improve knowledge and use of emergency contraception Provider/clinic level}

1. Assess knowledge of emergency contraception (EC) by using use self-administered, anonymous surveys

2. Dispel any myths or misinformation about EC by interviewing patients

3. Improve access and delivery of $\mathrm{EC}$ to adolescents:

- following are various types of models for health care delivery to adolescents:

a. specialized adolescent clinics

b. community-based health care facilities

c. school-based or college-based health services

d. community-based centers

e. pharmacies

f. outreach programs, such as mobile clinics

4. Provide confidential, youth-friendly clinic services

\section{Community/school level}

Reproductive and sexual health-education programs at schools.

\section{National/public policy level}

1. Public service announcements/campaigns

2. Television shows

3. Legislation

\section{World Health Organization framework for youth-friendly health services}

An equitable point of delivery is one in which:

- Policies and procedures are in place that do not restrict the provision of health services on any terms, and that address issues that might hinder the equitable provision and experience of care

- Health care providers and support staff treat all their patients with equal care and respect, regardless of status

An accessible point of delivery is one in which:

- Policies and procedures are in place that ensure health services are either free or affordable to all young people

- The point of delivery has convenient working hours and convenient location

- Young people are well informed about the range of health services available, and how to obtain them

- Community members understand the benefits that young people will gain by obtaining health services, and support their provision

- Outreach workers, selected community members, and young people themselves are involved in connecting health services with young people in the community

An acceptable point of delivery is one in which:

- Policies and procedures are in place that guarantee client confidentiality

- Health care providers provide adequate information and support, to enable each young person to make free and informed choices that are relevant to his or her individual needs, and:

- are motivated to work with young people

- are nonjudgmental, considerate, and easy to relate to

- are able to devote adequate time to their patients

- act in the best interests of their patients

- Support staff are motivated to work with young people and are nonjudgmental, considerate, and easy to relate to 
- The point of delivery:

- ensures privacy (including discreet entrance)

- ensures consultations occur in a short waiting time, with or without an appointment, and (where necessary) swift referral

- lacks stigma

- has an appealing and clean environment

- has an environment that ensures physical safety

- provides information with a variety of methods

- Young people are actively involved in the assessment and provision of health services

The appropriateness of health services for young people is best achieved if:

- Health services needed to fulfill the needs of all young people are provided, either at the point of delivery or through referral links

- Health care providers deal adequately with a presenting issue, yet strive to go beyond it, to address other issues that affect the health and development of adolescent patients

The effectiveness of health services for young people is best achieved if:

- Health care providers have required skills

- Health service provision is guided by technically sound protocols and guidelines

- Points of service delivery have necessary equipment, supplies, and basic services to deliver needed health services

\section{References}

1. World Health Organization. Global Consultation on Adolescent Health Services: A Consensus Statement. Geneva: WHO; 2001.

2. World Health Organization. Adolescent Friendly Health Services: Making It Happen. Geneva: WHO; 2005.

\section{Publish your work in this journal}

Open Access Journal of Contraception is an international, peerreviewed, open access, online journal, publishing original research, reports, reviews and commentaries on all areas of contraception. In addition to clinical research, demographics and health-related aspects, the journal welcomes new findings in animal and preclinical studies

Submit your manuscript here: https://www.dovepress.com/open-access-journal-of-contraception-journal

relating to understanding the biological mechanisms and practical development of new contraceptive agents. The manuscript management system is completely online and includes a very quick and fair peer-review system. Visit http://www.dovepress.com/testimonials.php to read real quotes from published authors. 